\title{
Exploring the Conceptual Frameworks Guiding Developmental Research and Practice in Higher Education: Some Challenges for Transdisciplinary Work
}

\author{
Nancy Budwig ${ }^{a}$ Achu Johnson Alexander ${ }^{b}$ \\ a Department of Psychology, Clark University, Worcester, MA, USA; ${ }^{b}$ Department of Psychology, Anna Maria College, \\ Paxton, MA, USA
}

\section{Keywords}

Transdisciplinarity $\cdot$ Relational-developmental paradigm • Agency · Process · Holism · Identity formation · Higher education

\begin{abstract}
This article examines questions initially raised at a meeting that took place 50 years ago on the topic of the development of knowledge in higher education where Jean Piaget coined the term "transdisciplinarity" and distinguished it from interdisciplinarity. We consider the question of why transdisciplinary scholarship has been so challenging for the field of developmental science. We argue that shifts in the guiding metatheoretical framework of theory and research, away from split-mechanistic paradigms and towards process-relational ones, do not always align with the conceptual frameworks used in educational practice. Using the example considered by Piaget and others at the original conference on higher education and the development of knowledge and also examining the domain of identity development, we find support for ways developmental scholarship has embraced the shift to a relational-developmental metatheory. In contrast, we argue that the relational-developmental paradigm has not been fully adopted by practitioners, with evidence of some using the Cartesian-split-mechanistic paradigm and
\end{abstract}

others using some aspects of the relational-developmental paradigm. We highlight the importance of examining the conceptual frameworks guiding developmental scholarship and practice, suggesting that alignment of conceptual frameworks is an essential ingredient for progress in transdisciplinary scholarship and practice to take place. Conceptualizations at the metatheoretical level condition each and every aspect of theory, research, and practice, giving meaning to both theoretical and empirical activities and guiding practice-based work. Debates often occur at the metatheoretical level, and thus are not open to empirical adjudication. We conclude that metatheoretical alignment between scholars and practitioners is critically important to transdisciplinary efforts in developmental science and therefore more attention to the metatheoretical assumptions of the process-relational paradigm is critical for work with practitioners to succeed.

(c) 2021 S. Karger AG, Basel

\section{Introduction}

Fifty years ago, Jean Piaget and several other academics and higher education leaders gathered for a seminar in France to examine how the study of the development of knowledge could contribute to issues of teaching and karger@karger.com

www.karger.com/hde

Karger"

(C) 2021 S. Karger AG, Basel 
research in universities around the globe (Apostel, 1972). The epistemology of knowledge was debated and considered in light of how best to organize universities for teaching and innovation. At that meeting, conclusions were drawn that are central to issues of the development of knowledge, particularly the ongoing discussions about the relation between theory and practice. The seminar brought together scholars who studied the development of knowledge with practitioners of higher education deeply aware of the daily practices at our institutions of higher learning seeking to bring about change.

It was at this meeting that Piaget coined the term "transdisciplinarity," and interdisciplinarity and transdisciplinarity were distinguished from one another. When Piaget introduced the term "transdisciplinarity" as something of an afterthought, its use did not go unnoticed at the meeting and the decades that followed. Piaget, drawing on his anti-positivist stance, adopted a systems approach to knowledge, arguing for the importance of knowledge in various disciplines to interact within a larger system of relations. Here, he distinguished interdisciplinarity - which implied cooperation between disciplines that have mutual impact on each from transdisciplinarity, about which Piaget (1972, p. 138) stated:

Finally, we may hope to see a higher stage succeeding the stage of interdisciplinary relationships. This would be "transdisciplinarity," which would not only cover interactions or reciprocities between specialised research projects, but would place these relationships within a total system without any firm boundaries between disciplines.

Jantsch (1972), in a paper that responded to Piaget's proposal about transdisciplinarity, agreed with Piaget's general position, but pushed further by stressing the importance of an integrated approach to knowledge that also highlighted the importance of considering the social purpose of knowledge. According to Jantsch (1972), "The essential characteristic of a transdisciplinary approach is the co-ordination of activities at all levels of the education/innovation system towards a common purpose" (p. 114). The emphasis on human activity and purpose brought to the foreground the consideration of the relation between disciplinary knowledge structures and the purposes to which knowledge is put to use.

While Piaget coined the term and got the discussion going, Jantsch's framework has been more influential to recent discussions and elaborations (Klein, 2009). For instance, Kockelmans (1979) highlights that across various uses of the term "transdisciplinarity" is the search for an overarching framework or worldview from which a par- ticular problem can be solved, and the importance of grounding education and research in more socially relevant ways.

Reading the papers, collected by Apostel (1972), by the academics and practitioners that resulted from that meeting in France and further discussions on interdisciplinarity and transdisciplinarity in the academy, we are struck by how much of the conversation rings true today as it did back then. Although our theories of human development and knowledge have continued to change, the concerns voiced still exist at colleges and universities today. With some notable exceptions, the majority of universities and colleges have not been structured based on what we know about human development and learning or the development of knowledge. This is not to say that the conference with its focus on defining the centrality of interdisciplinarity and transdisciplinarity has not had any impact. In fields such as environmental science and nanotechnology, the meeting has led to significant advances in new knowledge and practice (Klein et al., 2001; Mittelstrass, 2011). For instance, scholars who study sustainability science regularly meet up with practitioners whose everyday efforts aim to address sustainability issues to collaborate on knowledge creation as well as to consider best practices in sustainability efforts.

However, the field of developmental science has lagged significantly in this area. To state this bluntly, scholars of human development in general have not made significant progress in linking their work firmly to urgent complex societal problems. There have been pleas for theoretical work to align with application, and there have been suggestions for the importance for theoretical work to form the foundation of applied efforts in developmental science. However, these connections are too often unidirectional with basic researchers suggesting use of developmental theory and research, with little evidence of success. All too often, the notion of use and user is generic and underspecified, and only general reference is made to what some have called "mythical users," especially in funding proposals where the goal often is rhetorical and to show the value of the proposed research, rather than a strong belief in teaming up with specific practitioners (Shove \& Rip, 2000). At the same time, and as we will show, this is not a one-sided problem. Scholars of human development depend on the clear articulation of urgent societal problems, and often these are ill-defined by the complex range of practitioners who scholars aim to help, whether educators, parents and families, policy makers, or other practitioners seeking to improve developmental trajectories of individuals. As we will discuss, both schol- 
ars and practitioners bring conceptual frameworks to the work they do, and these framings influence the approaches taken and the relevance one finds in the work of one another.

We know from the conference 50 years ago that simply bringing theoreticians and practitioners together does not automatically assure success in aligning scholarship with practice, and even clarity of purpose is not a guarantee. Even though scholars and practitioners at the conference agreed on a set of problems, such as the belief that most students arrive at university unprepared for the learning expected of them (Briggs \& Michaud, 1972), the problems identified by both scholars and practitioners have endured.

We believe that the field of developmental science is positioned to make significant progress on the vexing issue of linking scholarship and practice. Recently, there has been significant discussion highlighting how important metatheoretical alignment is for advancing scientific activity. The field of developmental science has begun to discuss ways metatheory necessarily conditions what constitutes meaningful theory, method, and practice and is therefore not open to empirical adjudication. Without metatheoretical alignment, theoretical debates cannot be resolved through empirical means. In this article, we will review the momentum for changing conceptual frameworks in developmental science, and propose whether and how these changes in conceptual frameworks can contribute to an understanding of why transdisciplinary work has been so challenging in the developmental sciences. Our examination will focus on the momentum towards the relational-developmental paradigm and away from more Cartesian-split-mechanistic models, examining two concrete instantiations in different areas of developmental science inquiry. We then specifically examine the conceptual paradigm synergy between developmental scholarship and educational practice through analysis of two distinct areas of developmental theory and practice - namely knowledge development and identity construction in higher education, highlighting less synergy in one of the two areas. This then leads us to explore whether one reason why transdisciplinary work has been challenging for developmental science has to do with historical shifts and conflicting conceptual frameworks that researchers and practitioners bring to the table. Said differently, we do not need more findings, but rather reflection on and alignment of the conceptual frameworks used by developmental scientists and practitioners.

Conceptual Frameworks Guiding

Developmental Research and Practice

\section{Momentum for Changing Conceptual Frameworks in Developmental Science Theorizing and Implications for the "Gap" between Knowledge and Practice ${ }^{1}$}

In an important article in Human Development, Witherington et al. (2018) argued for the importance of recognizing the value of conceptual analysis, and in particular, the way this plays a role in helping organize and make sense of our everyday understandings of the world. These conceptual frameworks consist of what Overton (2015) and Witherington et al. (2018) have described as the belief systems and assumptions about ontology and epistemology that we bring to our work, both as individuals and as scholars. Evaluating existing scholarship, they have argued for the existence of a core metatheoretical divide in the developmental sciences that has implicitly framed a lot of discussions and work in the field. This divide has been described at the highest level as that between frameworks embracing the longstanding Cartesian-split-mechanistic paradigm and the relational-developmental systems paradigm (Overton, 2015; Witherington et al., 2018) (Fig. 1).

These two paradigms are distinct in at least three important ways that are depicted in Figure 2: views of the importance of the role of the organism (agency) in development, the centrality of studying dynamic and unique patterning in human development (process), and the view of the organism as a structured whole and its relationship to the environment (holism). First, in relation to the role of the organism in development, unlike the splitmechanistic paradigm, the relational-developmental paradigm holds a more active, self-organizing view of the organism and supports the view that across human development, organisms have agency. Second, regarding the examination of process in human development, the splitmechanistic paradigm views development in terms of an additive and linear model, while the relational-developmental paradigm highlights the processes of microgenetic and ontogenetic changes (Overton, 2015; Valsiner, 1998). Both kinds of metatheoretical paradigms can invoke fixed stages, but the relational-developmental paradigm need not (Tudge et al., 2016). Third, and central to the distinction between the two kinds of metatheoretical perspectives, is the relation between the organism and the context within which they develop. The split-mechanistic

\footnotetext{
We follow Overton (2013, p. 55) in simplifying the cumbersome language by referring to the framework that includes relationism as a worldview and relational-developmental systems as metatheory by using the phrase relational-developmental systems paradigm.
}

Human Development 2021;65:1-18 
Fig. 1. Worldviews and paradigms as they relate to theories and domains of inquiry. Adapted from Witherington et al. (2018).

Fig. 2. Components of the relational-developmental paradigm.
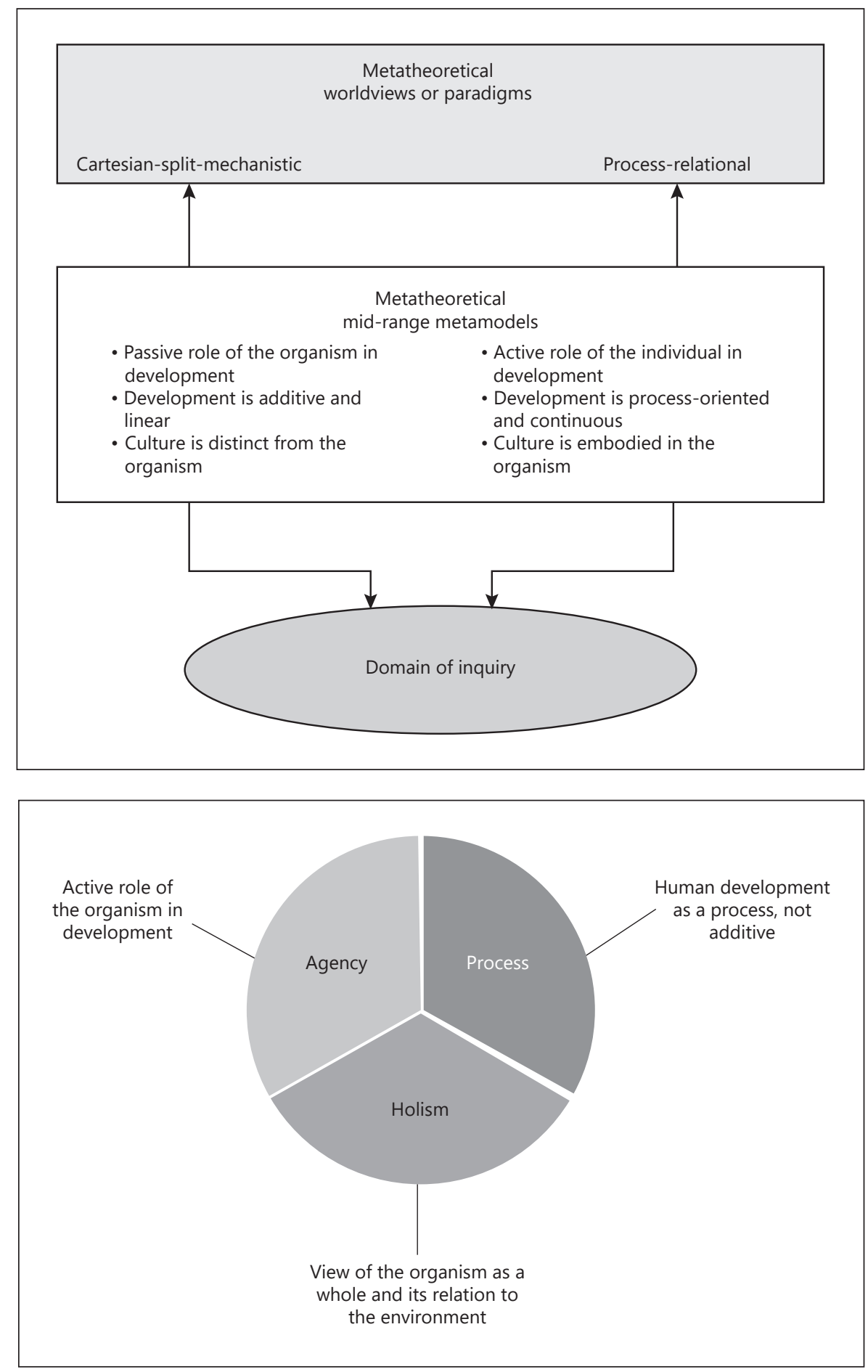

paradigm views the organism in terms of separate entities, viewing various parts of the human organism as modular, and with context and culture as separate and static entities. This contrasts with one of the central features of the relational-developmental paradigm, which adopts an integrated view of the organism (holism) as well as holistic relations between organism and environment. Culture, as we will see, is not an entity or a set of variables out there, but part of an integrated view of the organism. 
Central to the relational-developmental paradigm is a view of embodiment - the lived body bridges the biological, psychological, and cultural through its realization of the situatedness of humans. As noted by Mueller and Newman (2008, p. 333),

Human beings are not just contained in the environment as one independent object in another independent object (e.g., sand in a bucket). Rather, they intrinsically relate to the environment, which is why descriptions of human beings and their actions must include descriptions of part of the environment (Taylor, 1989).

It has been argued that the human condition and the ability to create tools and artifacts play a central role in human functioning and development and create a space where body, mind, and environment come together (Budwig, 2019; Di Paolo et al., 2018).

As Lerner (2016) has suggested, developmental science theory and research is at a crossroads. Without a doubt, there has been significant momentum in adopting what has been referred to as a relational-developmental systems paradigm in studying human development over the last few decades. This has resulted in an emerging sense that the field of developmental science has moved beyond what in Lakoff and Johnson's (1980) terms can be considered a view of the mind as container, and towards more embodied notions of mentality (Overton et al., 2008). The distinction between the Cartesian-split-mechanistic and relational paradigms has much to offer to the field of developmental science. We will also be extending the argument to the world of practice. More specifically, practitioners also bring conceptual frameworks to domains of practice in much the same way scholars bring frameworks to the domains of inquiry.

Not only has there been momentum for a shift in conceptual frameworks underlying developmental science research, this shift also has implications for the broader impacts of scholarly efforts in the world of practice. Two concrete instances exemplifying positive ways the relational-developmental paradigm has been employed in both conceptualizing scholarship and practice can be illustrated by drawing on the work of cognitive and moral development scholars. In her recent article in Human Development, Kuhn (2019) argues for the importance of framing critical thinking and its development as a dialogic and shared practice rather than as an individual skill or ability that develops independently. In this sense, critical thinking (which is often thought of as an essential cognitive skill) is viewed in light of related social and discursive developments. Viewing it as a dialogic and shared practice engaged in by peers rather than as an individual skill or

Conceptual Frameworks Guiding

Developmental Research and Practice ability leads Kuhn to make a series of recommendations about how schools can foster the development of critical thinking of students in primary and secondary settings. She notes that altered conceptualizations of critical thinking have impacted measurement tools, and illustrates ways these changes in conceptualization impact practices in schools. Similarly, Nucci (2016), in a compelling testimony at the National Academy about character development, shared the relational-developmental systems worldview and made similar claims about the relationship between conceptual framework, theory, research, and practice. He argued that his ongoing research with his collaborators (Gee \& Nucci, 2019; Nucci et al., 2015) shows how character does not exist as a distinct mental entity, but is best viewed as part of a broader developing system (of which morality is a part). This complex systems approach enables a person to engage the social world. Nucci et al. (2015) discuss and test out educational interventions, suggesting new educational practices that secondary schools can utilize based on the more dynamic approach to human functioning and development. In terms of character development, students do not need more teacher transmission of core ideas; rather, students need discursive tools with which to reason in everyday contexts.

Whether looking at critical thinking as Kuhn has done, or moral reasoning and character development as Nucci's work has highlighted, what holds this work together is the belief that development takes place when organisms actively construct meaning in and through interactions with others, especially peers, with guidance and support from more experienced others. Furthermore, both researchers not only design research based on explicit consideration of their theoretical framework which posits development as a process, but also explicitly design educational interventions that involve providing teachers with tools and protocols to foster these interactive patterns with students in attempts to enhance cognitive, social, and moral development. To this extent, these researchers have made important connections between changing worldviews in developmental theorizing and theories of change in schoolbased practices. We should note that the shift towards a relational paradigm is not unique to developmental science. Historical evidence can also be found for a gradual shift and momentum towards relational paradigms in psychological discourse. Gentner and Grudin (1985) examined nearly 100 years of writing in the journal Psychology Review and identified subtle evidence for the evolution of the kinds of metaphors researchers discussed, for instance, moving from vague metaphors involving animacy where mental phenomena are described in relation to 
creatures early on, to a later evolution of incorporating systems metaphors in the third and final phase of their analysis. More specifically, James (1905) compared the mind to an animate being in his statement that ideas struggle with one another, whereas many years later it was more common to conceptualize the mind in terms of physical or mathematical systems or analogical devices such as describing the human mind in terms of processes such as searching and retrieving. Gentner and Grudin (1985) argue that the system metaphor and the appeal to interdependent systems is a surface level indicator of the conceptual frameworks of the time. Empirical evidence of this sort suggests ways that the field of psychology has evolved in conceptual frameworks utilized in discussions of mental phenomena over many decades.

What is known about the conceptual frameworks that practitioners bring to their work? In this paper, we will examine this question and compare practitioner perspectives to those held by developmental scholars. Lakoff and Johnson (1980) have argued that metaphors have a profound impact on how humans think and act, are pervasive in everyday discourse, and are extensively used to guide human reasoning and action. For instance, Lakoff and Johnson (1980) have discussed how the mind tends to be viewed as a container, using a Cartesian-split-mechanistic framing. Recent examinations of lay persons' conceptual frameworks for knowledge are said to continue to robustly use mechanistic paradigms, such as employing a container model for the mind (Starmans \& Friedman, 2012). Looking more specifically at the development of knowledge, Carl Bereiter (2002) has argued that regardless of whether one looks at views of education from lay persons' acceptance of behavioralist theories or more constructivist views, the container metaphor (where the mind is viewed as a separate container-like entity) undergirds most thinking about knowledge. Thinking about knowledge at the supraindividual level is just not part and parcel to folk conceptions of knowledge and this, according to Bereiter, causes confusion since lay persons and theorists may use similar terminology with very different meanings drawing on distinct conceptual frameworks.

We argue that there are two important implications resulting from the changing conceptual frameworks guiding theorizing in developmental science. First, changing conceptual frameworks at the meta-level have influenced how scholars approach previously studied areas. This, then, can ultimately offer new insights into the implications for considering how users make use of particular findings. Second, changes in conceptual frameworks also impact our thinking about transdisciplinary approaches to developmental science, raising the important question of whether theorists and practitioners share similar conceptual frameworks and worldviews, especially when trying to mutually solve complex problems. We turn to consider two areas of human development scholarship that not only relate to these two points, but also tie back to the discussion of higher education and teaching that was the focus of the meeting where Piaget coined the term "transdisciplinarity." We will first examine theory and practice related to the development of knowledge and turn next to the development of identity and higher educational practice.

\section{The Relational-Developmental Paradigm, the Development of Knowledge, and Higher Education Practice}

There is little debate that the grand theories of human development in the 20th century significantly advanced our understanding of the development of knowledge and did so by emphasizing the organism's role in acting on and transforming knowledge (Piaget, 1967, 1974/1980). Furthermore, grand developmental theories such as those proposed by Piaget and Werner emphasized the importance of developmental processes in the unfolding of mental structures and moving from practical to symbolic planes (Piaget, 1954; Werner \& Kaplan, 1963).

By the 21st century, constructivist views of the development of knowledge impacted educational design and practice by adopting a more active view of the organism and examining knowledge development as a cognitive process that extends both microgenetically and orthogenetically. For instance, the importance of deep learning principles in discussions of knowledge development encouraged educational practices requiring learners to relate new knowledge to prior knowledge and experience (Bransford et al., 2000). Educational design in schools and higher education began to focus on the importance of integration of conceptual systems and highlighted the need to move from static knowledge handed down as is, to creating educational environments encouraging learners to examine and evaluate knowledge in light of accepted evidence and critical analysis. This view of how knowledge develops, referred to as deep learning approaches, has had a profound impact on educational practices and can readily be found in some visions of primary and secondary school and higher education practice, even if not fully implemented (Budwig, 2013; Budwig \& Alexander, 2020; Sawyer, 2014). Deep learning approaches adopt a relational worldview with regard to views of student 
agency, the importance of process in the construction of knowledge, and the holistic organization of the organism as learner. Nevertheless, they lack a framing of knowledge development as part of a larger holistic system acknowledging the relationship between the organism and culture. That is, knowledge development is often framed as an individual and decontextualized process.

In contrast to the decontextualized and individualistic accounts of knowledge development, much contemporary sociocultural scholarship about the relationship between knowledge, practice, and human development has emphasized holistic systems and the situatedness of knowledge (Bielaczyc et al., 2011; Budwig, 2013; Vygotsky, 1978; Wortham, 2010). On this view, knowledge is actively constructed by individuals as they participate in sociohistorical and cultural processes (Saxe, 2014; Vygotsky, 1978). To this extent, mental life and its development is grounded in sociocultural activities (Bruner, 1996; Nelson, 2017). We claim that three constructs from sociocultural accounts alter the way knowledge development is framed, all drawing upon a relational-developmental paradigm. These include scaffolding, knowledge building, and communities of practice. Without full understanding of the implications of these constructs, attempts to incorporate this more holistic conceptual framework into practice simply does not work as practitioners adopting a split-mechanistic framing would have divergent views of the organism and holism.

Drawing on Vygotsky's notion of the zone of proximal development, the scaffolding metaphor views the development of knowledge as the completion of complex tasks where learning takes place from interacting with more experienced others, going beyond what individuals know on their own. To this extent, knowledge takes place less through transfer from expert to novice and more through the social engagement with others in ongoing processes of interaction. To this extent, knowledge is not located in the heads of individuals but is constructed in and through interaction (Brown et al., 1989; Hanks, 1996; Moore, 2013). Brown et al. (1989, p. 33) argue:

To talk about academic disciplines, professions, or even manual trades as communities or cultures will perhaps seem strange. Yet communities of practitioners are connected by more than their ostensible tasks. (...) The culture and the use of a tool act together to determine the way practitioners see the world; and the way the world appears to them determines the culture's understanding of the world and of the tools. Unfortunately, students are too often asked to use the tools of a discipline without being able to adopt its culture. To learn to use tools as practitioners use them, a student, like an apprentice, must enter that community and its culture.

Conceptual Frameworks Guiding

Developmental Research and Practice
Central to this conceptual framework for understanding knowledge building is the view that the individual is actively asked to enter the culture and perform activities central to the community of practice. To learn in the discipline is not simply acquiring fixed knowledge but learning to refine, use, and build new knowledge in ways consistent with the disciplinary culture, rather than something handed down from experts to novices (Scardamalia \& Bereiter, 2014). Relating this framework to students, the development of knowledge entails learning how to perform and understand disciplinary procedures and practices central to problem solving in that area. Scaffolding allows students to engage in authentic activities that introduce them to the sense-making, reflection, and real problem-solving processes necessary to help students by making activities simpler so that learners can engage and learn in valuable ways (Reiser \& Tabak, 2014). As Brown et al. (1989) note, the practice of students in normal education contexts "is very different from what we have in mind when we talk of authentic activity, because it is very different from what authentic practitioners do" (p. 38).

One major way that knowledge has been said to be constructed is as part of broader social activities called communities of practice (Lave \& Wenger, 1991). Communities of practice consist of people who share a concern or a passion for something they do and learn how to do it better as they interact regularly. Three core elements of such communities include "mutual engagement," "joint enterprise," and "shared repertoire" (Wenger, 1998, pp. 72-73). It is within such communities that individuals come together and jointly practice using a shared repertoire of symbolic tools and artifacts, which have become part of the practice (Wenger, 1998).

Central to situated accounts of the development of knowledge and engaged learning is not simply individual acts of local practice, but rather the process by which participation involves becoming an increasingly active and engaged participant of a social community over an extended period of time and "constructing identities in relation to these communities" (Wenger, 1998, p. 4). That is, engagement is not simply viewed as local practicing or "doing," but also consists of the active engagement and changing ways individuals share engagement over sociohistorical time. On this view, the development of knowledge is conceptualized within a relational-developmental paradigm; it is process-oriented, holistic in that it involves cognitive, social and linguistic development, and socially situated in authentic and dynamic contexts.

Human Development 2021;65:1-18 DOI: $10.1159 / 000514553$ 


\section{Implications for Higher Education Practice}

While tremendous progress has been made in understanding the development of knowledge and the role of experience in learning, relatively little of this knowledge can be directly tied to how academic learning is structured in higher education. When developmental scholarship is cited, most frequently it is a general reference to the constructivist theorizing and philosophy of experience embedded in Piaget's (1967) and Dewey's (1933) frameworks often shared in teaching statements of new faculty under review. While claims about the lack of implementation of these newer theoretical models of the development of knowledge have also been made about primary and secondary education, most would argue that the work in schools is further along. For instance, Darling-Hammond et al. (2019) specifically address ways theory and practice link together in school settings based on their explication of new relational-developmental paradigms of knowledge development. In higher education though, curricular design typically is owned by faculty, most of whom have little training in human development and who hold different conceptualizations of learning and development than those embraced by development scholars. Faculty as practitioners bring to the design of curricular frameworks the worldviews they adopt towards knowledge. They also draw on broader frameworks of national and transnational organizations that support this work (Budwig \& Alexander, 2020). What conceptual frameworks do faculty, university officials, and national and transnational leaders bring to higher education practice involving students' development of knowledge?

By the start of the 21st century, two changes in higher education had taken place that led to new visions of higher education that, at first glance, seem tied to a new worldview of the development of knowledge within a relational-developmental systems paradigm. First, disciplines had begun considering what sort of knowledge is essential. As part of what has become known as the Tuning Project, international disciplinary groups began to reflect on questions of what it means "to know" in a given field, highlighting the need to go beyond transfer of knowledge from experts to novices (Budwig \& Alexander, 2020; Kehm, 2010; Reichert \& Tauch, 2005). A second kind of change, viewed in part as a reaction to the compartmentalization of knowledge in universities with the creation of the "major" and disciplines, has resulted in higher education leaders discussing the need to help students learn to connect fragmented knowledge especially from different disciplinary lenses and to apply that knowledge to new contexts. Consideration of both the integration and application of knowledge has been emphasized. By the early 2000s, the Association of American Colleges and Universities (2002), a leading voice in student learning in higher education, noted that a liberal education would ideally produce "integrative thinkers who can see connections in seemingly disparate information" (p. 21).

As part of broader national and transnational efforts, Humphreys (2005) has explored why learning outcomes such as new focus on integrative and applied learning were receiving so much attention in the early 2000s. She discussed not only linkages to the kinds of knowledge needed by employers in the 21 st century which is frequently mentioned, but also argued that the shift drew from evidence in the developmental and learning science asserting the importance of constructivist accounts of knowledge. Taking a process account, scholars such as Colby et al. (2003), Huber and Hutchings (2004), and Huber et al. (2005) argued for the importance of scaffolding, suggesting that higher education faculty play critical roles in guiding knowledge integration, as students increasingly come to do this only over time on their own. The focus on application was originally tied to learning and developmental science research. Over time though, and this is centrally important, as scaffolding from national or transnational supports faded and universities began working independently on reform efforts without the guidance of national or transnational leadership, and we believe the focus on engaged learning became integrated into available worldviews. That is, leadership at individual campuses often fell back on split-mechanistic frameworks suggesting that one develops knowledge and then takes it out into context to use it. Internships and other experiential projects also transformed into necessary elements not of the original construction of knowledge, but became viewed as tools for student preparation to enter the workforce and civic life, ready to work as part of interdisciplinary teams needed in the 21st century (Budwig \& JessenMarshall, 2018).

Moore (2013), in an excellent review of engaged learning in the academy, discusses what he calls the central paradox. While those studying the development of knowledge have viewed practice-based learning as central to the development of knowledge, colleges and universities have for the most part viewed experiential learning as something outside of the academic realm, or at best something that augments or supplements the development of knowledge that first takes place in the classroom. We argue that this paradox stems from the underlying worldviews higher education leaders and faculty bring to the table. Lay 
conceptions of knowledge build off the container model (Lakoff \& Johnson, 1980) and often lack the embodied and relational-developmental systems paradigm necessary to implement the vision consistent with the systems orientation towards agency, process, and holism required of the relational worldview.

Eyler (2009, p. 29), one of the few scholars who has simultaneously spoken about students' development of knowledge and higher education vision, has noted:

There is a profound mismatch between how students learn in the classroom and how they will later learn in the community (Resnick, 1987). In the workplace or in addressing community issues, learning often occurs collaboratively, is organized around concrete situations, makes use of tools and resources, and is iterative, whereas classroom-based learning often involves decontextualized knowledge, manipulation of abstract symbols, and highly individual efforts. Knowledge in the classroom tends to be compartmentalized into disciplines, whereas in use in the community or workplace it tends to be organized around problems or domains of practice.

We claim that even if new worldviews have influenced scholars studying knowledge development, it will be necessary to make sure key elements of the worldview upon which this body of scholarship rests is better understood in practice communities. For instance, university faculty and leaders will need to better understand that students need extensive training before and during experiential learning, and the experiential and classroom learning should be mutually supportive (see Moore, 2013). In addition, holistic views of student development will be necessary in that the development of knowledge goes hand in hand with interest and agency in learning, as well as building a social and professional identity around the engagement activities. Students' development and application of knowledge involves more than participating in projects or internships; the process of reflecting on and sharing one's growing knowledge through the public display of artifacts and other symbolic tools that members of a community of practice use when engaging in activities is central. Such artifacts offer a mechanism for making knowledge visible to one another (Lave \& Wenger, 1991; Rogoff, 1995). This transition to communal sharing of knowledge does not come easily for students who have been trained to view the development of knowledge and learning individually and will need significant scaffolding in the art of collaborative learning (Herrenkohl \& Mertl, 2010). Language as well as other symbolic means offer metacognitive guidance for solving complex problems collaboratively. For example, Bielaczyc and colleagues working within $\mathrm{K}-12$ education have designed scaffolding tools that highlight particular knowledge-building communicative moves for practice and reflection as a means of supporting learners and others to come to a collective improvement of ideas (Bielaczyc \& Collins, 2006; Scardamalia \& Bereiter, 2006). These tools resemble some of the processes and tools described by Kuhn (2019) in her discussion of secondary students' development of critical thinking.

In summary, we have made three claims in this section about the relational-developmental systems paradigm and the development of knowledge. First, we have argued that the worldview associated with the relational-developmental systems paradigm has significant implications for reimagining higher education teaching and student learning. Second, we have argued that a modern-day relational-developmental systems paradigm has advanced theorizing by considering a more holistic view of knowledge and its development. Here, we especially focused on the work of a situated relational-developmental paradigm with the focus on contextualized accounts of knowledge in practice and notions of scaffolding, knowledge building within authentic practices, and the notion of communities of practice as central to knowledge building. Third, we have argued that while higher education has made some progress in creating a new vision, work on implementation has been more difficult and not been fully successful. We argue that a partial explanation of this stems from the fact that those implementing the vision do not share the relational-developmental worldview, especially the situated view of embodiment central to implementation. The implementation efforts are reinterpreted in light of more traditional folk theories that imagine knowledge as needing first to get into the mind and then be deployed out into the world of practice. Thus, while there is mutual belief in more engaged styles of learning, differences in the underlying conceptual frameworks about how engaged learning works make this work challenging.

\section{The Relational-Developmental Paradigm, Identity Development, and Higher Educational Practice}

In this section, we turn to consider the relational-developmental systems paradigm and identity development, arguing for a different relationship between scholarship and practice. First, we consider a body of theory and research by scholars studying emerging adulthood, who consider the identity formation process and role of self in the meaning-making process. More specifically, we will argue how common conceptual frameworks have led student affairs practitioners to structure the college expe- 
rience in ways supported by identity development scholarship. We also will note ways in which some practitioners outside of the student affairs area of higher education hold less aligned of conceptual frameworks, especially when we turn to consider academic aspects of student development and linkages to identity formation.

At first glance, consideration of students' identity development has little connection to higher educational practice. It was not mentioned directly at the workshop 50 years ago, though the American focus on the role of students' co-curricular activities on their learning was considered. Over the past decades, as scholars have examined development within more holistic worldviews that link social-emotional development with cognitive development and learning, the relation of identity development and higher educational practice has received more attention. College has been described as a space separated from the rest of society where traditional-aged students (18-21 years) can explore identities and possibilities related to relationships, love, and work, and as a space where many of the responsibilities of adult life are kept on hold (see Arnett, 2016). College provides a fertile ground to engage in precisely the sort of identity exploration (Arnett, 2016; Magolda \& Taylor, 2016) said to enhance student development for traditional-aged students.

A core aspect of identity exploration, according to the emerging adulthood approach, involves the organism's search for a sense of self (Schwartz et al., 2016). Emerging adults are said to be engaged in autonomy taking, cognitive acumen, and identity-based work, all part of a process that has been described as an individual struggle to make meaning and write the first drafts of their life stories (Magolda \& Taylor, 2016; McAdams, 2013, 2016). The emphasis in such work is on a series of questions young people face, including "Who am I?", "How do I relate to others?", and "What do I want myself to be?" as they search for meaning in life and consider different possibilities. Initially, young people answer these questions using externally-defined formulas but increasingly adopt more internally-defined purposes. This shift from more externally-defined to more internally-driven formulas has been described by Magolda (2009) as self-authorship. This internal dialogue is successfully navigated and resolved when the individual feels agentic, self-driven, and socially connected (Magolda, 2009; Parks, 2000).

As individuals gather more autonomy from parents and develop self-defined meaning-making structures, they make advancements towards writing their life narratives on their own terms (McAdams, 2013). McAdams terms this challenge as life authorship where:
... emerging adults aim to reconstruct the past and imagine the future in such a way as to provide their lives in full with some semblance of meaning, unity, and purpose ... the self becomes fully engaged as an autobiographical author (the I), even as the I continues to construe itself (the $\mathrm{Me}$ ) as a social actor and motivated agent. (p. 280)

The process of identity formation is viewed as one that increasingly separates self and other, and the emerging adult is said to come to rely on self-defined norms and formulas rather than societal-based standards (Magolda \& Taylor, 2016). The capacity to coordinate the internal voice with that of an external standard initiates the writing of a self-defined life narrative and the resulting entry into adult life.

It has been noted that although adolescents and emerging adults have been described as self-absorbed, these are stereotyped descriptions and scholars have noted that adolescents and emerging adults seek a greater sense of purpose and belonging than often given credit. They not only are working on questions of "Who am I?", but show intense concern for the world they will inherit and their involvement in making it a better place (Sokol et al., 2018). And it is here, in the study of identity formation and character development, that Sokol et al. (2018) argue that the relational-developmental paradigm can provide helpful framing to their research to the extent that one examines holistically the relational aspects of adolescent and emerging adult students and the supports available. For instance, in their studies of first-nation youth across two historical time periods, they seek to understand the rich interplay between youth agency and cultural resources. More specifically, they have examined how youth make use of or fail to use family, learning institutions, and community and cultural resources as part of self-interpretive aspects of identity formation. Sokol et al. (2018) argue that young people can draw upon college and community experiences in ways that help build resilience and promote identity formation, especially for youth who are not experiencing a meaningful vision of their future. To this extent, college can provide a safety net to those otherwise at risk. Sokol et al. (2018) suggest that the relational-developmental paradigm helps conceptualize "how social contexts intersect with psychological resilience in young people and their communities" (p. 241).

The approach to identity formation reviewed here embraces several aspects of the relational-developmental systems paradigm. The notion of emerging adults engaging in an extended phase of meaning-making that involves linkages between cognitive, emotional, and social development is at the heart of this body of work. Identity 
formation is viewed dynamically as an individual meaning-making process, using experiences with others, to help shape an individual's growing sense of self. To this extent, identity formation and meaning-making are socially situated, with context and culture having bidirectional influences on identity formation.

\section{Implications for Higher Education Practice}

Consistent with the relational-developmental paradigm, one of the major developments in higher education in the United States has been consideration of the whole student. Most campuses have a growing emphasis on supporting the social-emotional development and general well-being of students. Interestingly, this has been structured in a way that does not embrace holism to the extent that there has been compartmentalization with units of student affairs being built up to support students' social development, of which identity development has often been viewed as a central part, distinct from faculty efforts to support the development of knowledge in the academic arena. Much of the discussion about taking a wholestudent approach and efforts at programming has taken place on US campuses and within the areas of student affairs and alumni relations (Murray \& Arnett, 2019). Since student affairs professionals often have training in higher education and student development, there has been more overlap between theory and research carried out by scholars working on identity formation and practice-based approaches drawing on this work. The question we will turn to now relates to the conceptual frameworks those implementing education practice draws upon when doing this work, and in particular the extent to which aspects of the relational-developmental systems paradigm are present or whether mechanistic conceptualizations are found. In particular, we will consider the views of the student and whether they are considered agentive, whether development is viewed as a process, and the extent to which a holistic view of the student is considered and whether and how the connection between student and environment is conceptualized.

Emerging adult theorists argue that, as agents of their development, college students explore "alternative political perspectives, working with people from different social backgrounds, and wrestling with a range of perspectives on social issues" (Flanagan \& Levine, 2010, p. 160). Furthermore, trying out courses and changing college majors are decisive steps towards confirming their career choices (Schwartz et al., 2016). Through these career ex-

Conceptual Frameworks Guiding

Developmental Research and Practice plorations, emerging adults begin to develop an understanding of what they excel in or enjoy doing the most and deepen their understanding of the "Who am I?" question.

As agents, students also are said to have the opportunity to draw upon learning practices in higher education that engage students to work collaboratively and develop interpersonal competence in ways that contribute to the development of personal and social responsibility (Magolda, 2008). Such intentionally designed pedagogies and learning experiences are said to broaden students' awareness of real-world experiences that promote civic-mindedness and capabilities to take on adult roles and generally assist students on their journey to form relational identity so central to defining how they relate to others (Magolda, 2008). Note that students are expected to actively construct their identity across time and space.

Higher education practitioners embrace the importance of process, highlighting that students work on identity exploration across the college years, as they are said to gradually integrate their social and personal identities into a coherent or holistic identity. For instance, Azmitia et al. (2008) found that first-year college students discussed gender, ethnicity, and social class in isolation while seniors stated a more sophisticated understanding of how their ethnic background and gender identities influenced their college major decisions and career choices. Azmitia et al. (2008) argue that the college context offers the privilege to engage in a prolonged period of identity exploration that began in adolescence and progresses through a process of individual exploration towards a more intertwined and holistic sense of their identities during the emerging adulthood years.

Relational frameworks highlight the holistic nature of development, both within the organism and between the organism and contexts within which they develop. Strange and Banning (2015) have outlined specific intentional aspects of college and university design that are critical to optimal identity formation. For instance, student success depends on a nested set of conditions including inclusion and safety, student engagement, and sense of community (Strange, 2019). According to Strange, these elements invite the "explorative creative processes of emerging adults at a time when they are most vulnerable, but also most ready to pursue the path of this period of life" (p. 148). Furthermore, Strange, drawing on Parks' (2000) notion of mentoring communities, clarifies specific environmental design features that facilitate emerging adults' finding meaning and purpose. These include such features as "networks of belonging" and finding a sense of purpose (Parks, 2000, p. 146). In addition to campus lead- 
ers recognizing the importance of infusing a sense of belonging into the campus events students experience from their first days on campus (e.g., orientation, pep rallies, student clubs and organizations), student affairs leadership has increasingly articulated the need to do more. In particular, practitioners have highlighted the importance of prioritizing inclusion and security, and to focus on events targeted at specialized groups including, for instance, LGBT students, students of color, and international students (Strange, 2019). When structured well, Strange (2019) argues that higher education institutions not only provide space but also advice and mentoring to help emerging adults chart pathways to success. Throughout this work, one finds arguments for the importance of scaffolding the students holistically as they engage in sense-making activities across the college years through coursework, student-faculty advising, and extracurricular activities.

Two points are interesting about work in the area of linking higher education design to foster identity formation around emerging adulthood theory and research. First, higher education leaders align well with the conceptualization of emerging adult scholars who view identity formation in college-going emerging adults as part of an ongoing process that involves scaffolding to support pathways to student success (Strange, 2019). Nevertheless, while student affairs professionals have implemented the kind of supports mentioned by scholars studying identity development, such as mentoring communities or networks of belonging as described by Strange (2019), this work has typically not been successfully extended to academic contexts. Few faculty have focused on how collegeattending students' identity formation may develop through participation in the sorts of engaged learning pedagogies found in some academic settings. As was noted above, according to Wenger (1998), learning and identity are part of the same situated experience. The value of participating is not so much tied to specific acts of task knowledge acquired, but acquiring a deeper sense of what it means to be a member of a specific (academic) community. This indicates that perhaps the divide between academics and identity formation may be a result of the siloed nature of institutional structures separating academic and student development which themselves may be built off of the Cartesian-split-mechanistic paradigm noted to guide many academics' conceptualization of development (see Budwig \& Alexander, 2020). The case of identity formation supports a different relationship between scholars and practitioners, one where alignment is possible and joint work sought out (Murray \& Arnett, 2019).

\section{Discussion}

Since being coined 50 years ago by Jean Piaget, the notion of transdisciplinarity has been growing in interest. It has led to the idea that knowledge building in the academy must be better anchored in the world of practice, in terms of our approaches in the academy towards both teaching and research. First, over the last decades, there has been a changing view of knowledge that highlights the importance of students' active engagement in learning, and the importance of students being able to also apply their knowledge in new situations. With regard to research, there has been increased interest in more directly anchoring researchers' new knowledge with the world of practice (Cantor et al., 2019; Darling-Hammond et al., 2019; Osher et al., 2020). Looking specifically at higher education, we have illustrated some examples of researchers who have successfully done just this at the individual level. We also highlighted how developmental science and those interested in the science of learning have linked up with educators to better design environments where what we know about the science of learning and development impacts classroom and school design. We noted though that this work primarily has been limited to primary and secondary school settings and not been fully extended to work in higher education circles and that generally, across the developmental sciences, transdisciplinary efforts are at best challenging and often do not materialize in practice.

In our examination of the challenge of transdisciplinary work in developmental sciences, we explored the role that conceptual frameworks play. Here we noted, for instance, that there has been growing momentum in the developmental sciences in developing theory and research using what has been referred to as a relationaldevelopmental paradigm. Drawing on work of others, we provided evidence for this shift generally in psychology, as well as in the field of human development, that suggests that the conceptual frameworks researchers bring to their work, emphasize an increasingly agentive, process-oriented, and holistic view of development. We raised the question of whether practitioners have experienced a similar shift, noting that a wealth of evidence has suggested that our everyday structuring of knowledge, mind, and identity has largely embraced the Cartesian-splitmechanistic paradigm. We were curious whether a specific analysis of scholarship and practice would reveal different conceptual frameworks underlying the work, and how that played out in terms of the success of transdisciplinary efforts. 


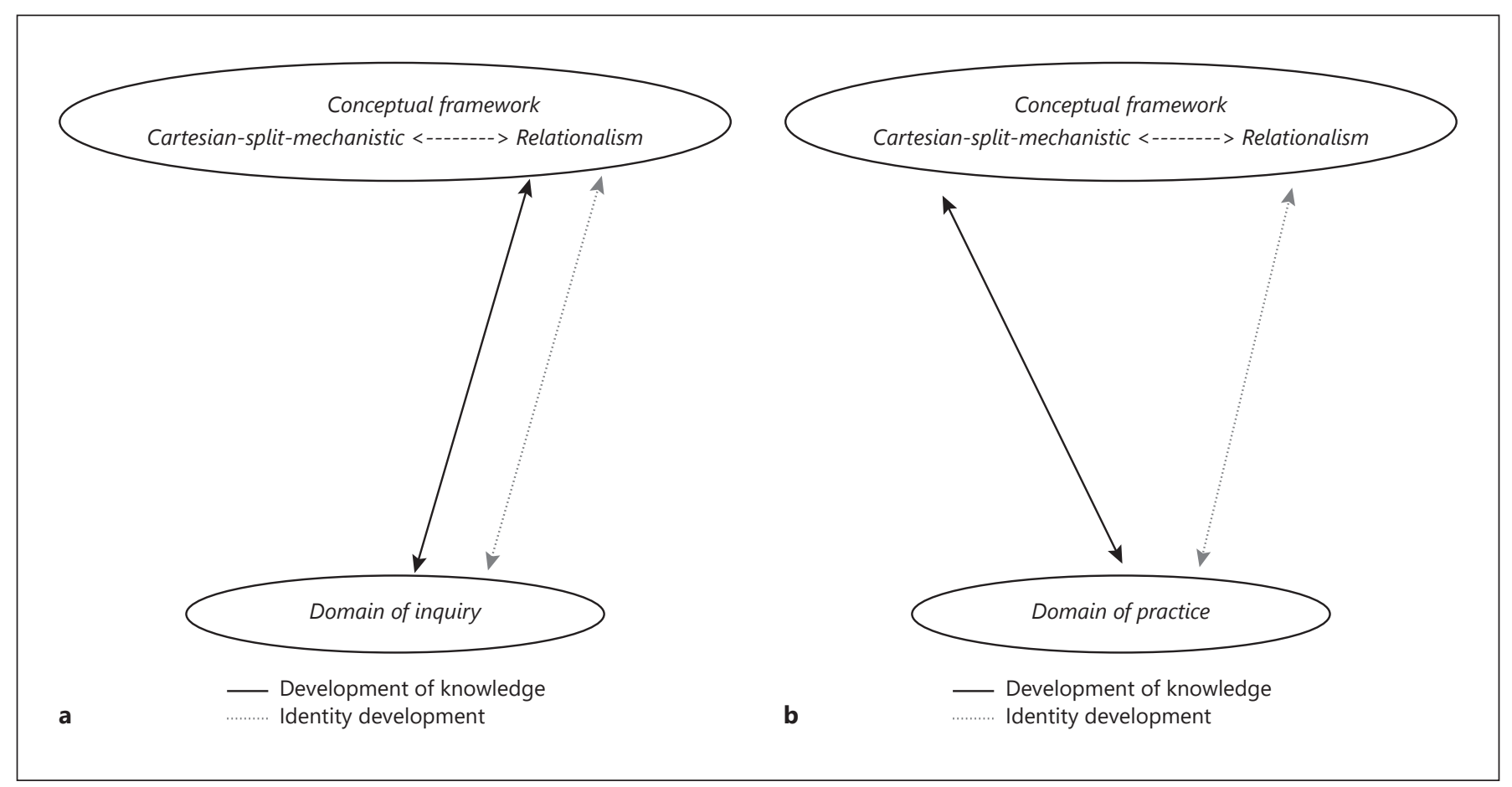

Fig. 3. a Scholars' dominant conceptual frameworks. b Practitioners' dominant conceptual frameworks.

We looked at two domains of developmental scholarship and their application to higher educational settings, focusing first on the domain of the development of knowledge and next on identity formation. While we approached the cases individually, we turn now to pull together what we learned about the dominant conceptual frameworks used by researchers in these areas, as well as those used by practitioners. Because our findings are nuanced, there is the need to carefully unravel the relationship. We will turn to do this now, and follow after that with a discussion of what these findings suggest about next steps pertaining to transdisciplinary work.

Figure 3 draws upon the model depicted in Figure 1 adapted from Overton (2015) and Witherington et al. (2018) that depicts the conceptual context of the Cartesian-split-mechanistic and relational-developmental paradigms. In Figure 3a, we examine the dominant conceptual frameworks of scholars and in Figure $3 \mathrm{~b}$ we examine the dominant conceptual frameworks of practitioners in each of the two domains of inquiry we examined (e.g., the development of knowledge and identity).

Figure 3a shows that in both domains of inquiry, current scholarship is aligned with the relational-developmental paradigm. This is consistent with prior work we reviewed by others (Lerner, 2016; Overton, 2015; With- erington et al., 2018), who have argued that scholarship in the developmental sciences is increasingly embracing the relational-developmental paradigm. This is interesting in that Glick (1992) noted that the relational aspects of some developmental theorists, such as Werner's organismic theory, proved challenging for developmental scholars to understand several decades ago, most of whom not only held different theoretical perspectives, but also grounded their work in the Cartesian-split-mechanistic paradigm at the time.

Figure $3 \mathrm{~b}$ shows something more complicated. Here we see that practitioners embrace both split-mechanistic and relational-developmental models. When looking at the development of knowledge, we found that practitioners pretty consistently showed evidence of the splitmechanistic paradigm, very much sticking to the "mind as container" metaphor. In contrast, within the domain of identity development, we found that student affairs practitioners adopted the relational-developmental paradigm. At the same time, other individuals around the student affairs officials and the organizational structures within which the student affairs professionals operated were less aligned with the relational-developmental paradigm and instead adopted a Cartesian-split-mechanistic framework. In short, while student affairs segments of 


\begin{tabular}{|l|l|l|}
\hline $\begin{array}{l}\text { Transdisciplinary } \\
\text { role }\end{array}$ & $\begin{array}{l}\text { Domain of inquiry: } \\
\text { development of } \\
\text { knowledge }\end{array}$ & $\begin{array}{l}\text { Domain of inquiry: } \\
\text { identity formation }\end{array}$ \\
\hline Scholar & $\begin{array}{l}\text { Relational- } \\
\text { developmental }\end{array}$ & $\begin{array}{l}\text { Relational- } \\
\text { developmental }\end{array}$ \\
\hline Practitioner & $\begin{array}{l}\text { Cartesian- } \\
\text { split-mechanistic }\end{array}$ & $\begin{array}{l}\text { Relational- } \\
\text { developmental }\end{array}$ \\
\hline
\end{tabular}
$\square$ Split-mechanistic worldview is dominant
$\square$ Relational-developmental worldview is dominant

Fig. 4. Alignment of conceptual frameworks between scholars and practitioners.

practice align with scholars examining identity formation in ways central to student success, the joint work begins to break down or be lacking when practitioners from academic arenas (faculty and university leadership) who hold mechanistic views become involved. Across both domains, practitioners from academic areas or those not specifically trained in student development were less aligned with scholars in that area.

Figure 4 pieces together these arguments. It shows that in general, scholars were more aligned with one another than were practitioners when it came to the dominant conceptual frameworks used in their work. Practitioners in the student affairs area worked within the relationaldevelopmental paradigm as they designed programming and practices to enhance student identity development central to student success. This shows that practitioners can and do utilize the relational-developmental paradigm. Still, we found ample evidence of a lack of alignment between scholars and practitioners in terms of the conceptual frameworks underlying their scholarship and practice in the development of knowledge domain.

Our argument goes beyond an examination of what scholars versus practitioners use as dominant conceptual frameworks. We believe that alignment between scholars and practitioners is central for transdisciplinary work. In order for scholars and practitioners to work together, they need to acknowledge the frameworks they bring to their efforts. Too often these frameworks are invisible and yet significantly hamper efforts. We also have noted that adopting a conceptual framework is not necessarily something that practitioners adopt and continue to embrace. For instance, we have argued in our examination of the domain of the development of knowledge that while at times practitioners can adopt a relational-developmental framework, especially with support from others adopting such a framing, this framing is fragile. Consistent with developmental work on scaffolding, over time and with- out support of others embracing a relational perspective, practice gets reframed in terms of a split-mechanistic paradigm, suggesting the importance of deeply examining the conceptual frameworks of practitioners. We have also noted that the split-mechanistic paradigm not only runs deep in higher education, but that the very organization of the university with its siloed distinction between academic and student support can impede progress (Budwig \& Alexander, 2020), suggesting ways the organization of the university is centrally involved in or impedes transdisciplinary efforts. A central argument running throughout our review of the two domains of inquiry and practice is that alignment between scholars and practitioners is central to solving complex problems together.

This last point brings us to a consideration of the implications of the argument we have built here. Developmental scholars are showing momentum towards adopting a relational-developmental paradigm, and until recently, this shift in paradigm was implicit in scholarly work. Our work highlights the importance of scholars to be explicit about the conceptual frameworks guiding their scholarship. This is not only important within the field of scholarship (as in recent discussions in Human Development and elsewhere), but also when working with practitioners. Scholars and practitioners may be using similar vocabulary, but alignment of the often invisible conceptual frameworks is key to problem framing and problem solving central to transdisciplinary work.

Our work, when combined with others, reveals that practitioners often work with different conceptual frameworks and currently are more inclined to draw upon Cartesian-split-mechanistic models. We believe this suggests the urgent need for scholars to accelerate discussions of the implication of new conceptual frameworks of human development in order not only to allow progress in theorizing, but also for transdisciplinary efforts to be successful. The relational-developmental paradigm comes up against some of the metaphoric ways teachers and other practitioners conceptualize human development, suggesting the importance for dialogue about these issues. There is substantial need for extensive consideration about how to go about this. Recognition alone by scholars is not enough. Scholars will need to consider ways to better explain the difference in conceptual frameworks. The English language is filled with metaphors that vividly portray mental phenomena in terms of a Cartesian-splitmechanistic paradigm. What is needed are compelling ways to help practitioners conceptualize human development in more relational ways. Furthermore, professional development and training that explicitly address these as- 
sumptions which implicitly guide our work will be needed in order for new conceptual frameworks and theories to be successful in shifting practice within the area of developmental science.

This brings us to two kinds of implications of our conclusions. First, we examine the specific implications for linkages between developmental science scholarship and higher education practice. We believe that in order for transdisciplinary progress to be made in higher educational reform, the relational-developmental paradigm must guide all individuals involved with curricular reform efforts and student learning. Scholars and practitioners need to consider the implicit assumptions they hold about how humans develop as they engage in reform efforts. In fact, the very nature of how professional development for faculty (too often with one-time lecture or demonstrations of technology or other practices) will need to examine underlying assumptions about learning and development and show ways human development and learning is grounded within a relational-developmental paradigm. Examples of this are beginning to take place in primary and secondary education contexts, and professional development activities are being designed to assist teachers with understanding assumptions they hold about learning and development, as well as the implications of new research for classroom practices (see Kuhn, 2019; Moon et al., 2012). For this work to be successful in higher education, it will take combined efforts of faculty and staff as well as learning and developmental science scholars to move forward with explicit discussion of the conceptual frameworks that are brought to these joint efforts often left tacit.

We believe, though, that the implications of this work go beyond our focus on developmental scholarship and practice pertaining to higher education or the particular domains of inquiry we have examined. Our central claim is that a necessary feature of transdisciplinary work involves the explicit consideration of conceptual frameworks. It has become increasingly clear that the conceptual frameworks scholars bring to the problem areas they study deeply impact the findings and conclusions drawn. We argue that one challenge for transdisciplinary work in the developmental sciences has been that scholars and practitioners often have fundamentally different conceptual frameworks. Without alignment of these fundamental worldviews, little progress can be made. We mean this in the widest sense. Our examples showed how even when scholars and practitioners who work together can adopt similar conceptual frameworks, as was the case in some of the identity development scholarship and practice, this work often hits up against larger structural constraints and design features involving conceptual frameworks of those not present at the table. For instance, scholars working on identity formation and student affairs leaders have been able to begin to design programming in light of an alignment of worldview, but run into institutional breakdowns because institutions of learning themselves have been designed based on conceptual frameworks not shared by those doing the work. This makes clear that developmental scholars have a role to play in helping the public understand that scholarly work has moved towards new conceptual frameworks embodied in the relational-developmental paradigm and in highlighting problems with the split-mechanistic paradigm in order for our work to have impact.

We noted in the opening paragraph of this article that 50 years ago Piaget coined the term "transdisciplinarity" and that since that point in time such work, even when valued, has been challenging to enact. Many current discussions of higher education identify problems identified by Piaget and his colleagues at the workshop 50 years ago, showing that the issues were known but that the problems identified have been difficult to resolve. We have argued that one reason why developmental science has lagged behind other fields in engaging in transdisciplinary work is because the folk theories and conceptual frameworks employed by developmental scholars and practitioners often are at odds. Prior work in developmental science has shown that the field has gained momentum in adopting the relational paradigm that scholars such as Piaget embraced. Scholars discussing metatheories and conceptual frameworks in developmental science have taken an important first step in unpacking the assumptions underlying developmental research. We need to go further and examine worldviews as they relate to issues of practice. Better metaphors are needed to help explain the relational-developmental systems paradigm. If these steps are taken, we believe that in the coming years scholars of developmental science and those interested in improving the developmental opportunities and lives of individuals across the lifespan can productively move forward in ways that are mutually beneficial.

\section{Acknowledgment}

We acknowledge the assistance of Michael Bamberg in reviewing and editing the manuscript, and thank two anonymous reviewers for feedback that improved the quality of the manuscript.
Conceptual Frameworks Guiding

Developmental Research and Practice
Human Development 2021;65:1-18 DOI: $10.1159 / 000514553$ 


\section{Statement of Ethics}

The authors have no ethical conflicts to disclose.

\section{Conflict of Interest Statement}

The authors have no conflicts of interest to declare.

\section{Funding Sources}

No external funding was received for writing this paper.

\section{Author Contributions}

N. Budwig played a central role in crafting the conceptualization of arguments made in this paper and the interpretation and implications for higher education. A.J. Alexander made a substantial contribution in the conception of the work on emerging adulthood and identity formation and assisted with conceptualizing the arguments made. Both authors played a central role in drafting the work and in revising it critically as well as in the final approval of the version to be published. Both authors agree to be accountable for all aspects of the work in ensuring that questions related to the accuracy or integrity of any part of the work are appropriately investigated and resolved.

\section{References}

Apostel, L. (Ed.) (1972). Interdisciplinarity: Problems of teaching and research in universities. Organization for Economic Cooperation and Development.

Arnett, J. J. (2016). College students as emerging adults: The developmental implications of the college context. Emerging Adulthood, 4(3), 219-222. 2167696815587422

Association of American Colleges and Universities (2002). Greater expectations: A new vision for learning as a nation goes to college: National Panel Report. https://www.aacu. org/sites/default/files/files/publications/ GreaterExpectations.pdf.

Azmitia, M., Syed, M., \& Radmacher, K. (2008). On the intersection of personal and social identities: Introduction and evidence from a longitudinal study of emerging adults. New Directions for Child and Adolescent Development, 120(120),1-16.https://doi.org/10.1002/ cd.212

Bereiter, C. (2002). Education and mind in the knowledge age. Lawrence Erlbaum Press.

Bielaczyc, K., \& Collins, A. (2006). Fostering knowledge-creating communities. In A. M. O’Donnell, C. E. Hmelo-Silver, \& G. Erkens (Eds.), Collaborative learning, reasoning, and technology (pp. 37-60). Lawrence Erlbaum Associates.

Bielaczyc, K., Kapur, M., \& Collins, A. (2011). Cultivating a community of learners in K-12 classrooms. In C. E. Hmelo-Silver, A. M. O’Donnell, C. Chan, \& C. A. Chinn (Eds.), International handbook of collaborative learning (pp. 233-249). Routledge. https://doi.org/ 10.4324/9780203837290.ch13

Bransford, J. D., Brown, A. L., \& Cocking, R. R. (Eds.) (2000). How people learn: Brain, mind, experience and school. National Academy Press.

Briggs, A. \& Michaud, G. (1972). Problems and solutions. In L. Apostel (Ed.), Interdisciplinarity: Problems of teaching and research in universities (pp. 185-252). Organization for Economic Cooperation and Development.
Brown, J. S., Collins, A., \& Duguid, P. (1989). Situated cognition and the culture of learning. Educational Researcher, 18(1), 32-42. https:// doi.org/10.3102/0013189X018001032

Bruner, J. (1996). The culture of education. Harvard University Press.

Budwig, N. (2013). The learning sciences and liberal education. Change. The Magazine of Higher Learning, 45(3), 40-48. https://doi.org /10.1080/00091383.2013.787271

Budwig, N. (2019). Book review of Linguistic Bodies: The Continuity between Life and Language by Ezequiel A. Di Paolo, Elena Clare Cuffari and Hanne De Jaegher. Human Development, 62(4), 219-22. https://doi. org/10.1159/000500176

Budwig, N., \& Alexander, A. J. (2020). A transdisciplinary approach to student learning and development in university settings. Frontiers in Psychology, 11, 576250. https://doi. org/10.3389/fpsyg.2020.576250

Budwig, N., \& Jessen-Marshall, A. (2018). Making the case for capstones and signature work. Peer Review: Emerging Trends and Key Debates in Undergraduate Education, 20(2), 4-7. https://www.aacu.org/peerreview/2018/ Spring/Analysis

Cantor, P., Osher, P., Berg, J., Steye, L., \& Rose, T. (2019). Malleability, plasticity, and individuality: How children learn and develop in context. Applied Developmental Science, 23(4), 307-337. https://doi.org/10.1080/10888691. 2017.1398649

Colby, A., Ehrlich, T., Beaumont, E., \& Stephens, J. (2003). Educating citizens: Preparing America's undergraduates for lives of moral and civic responsibility. Jossey-Bass.

Darling-Hammond, L., Flook, L., Cook-Harvey, C., Barron, B. \& Osher, D. (2019). Implications for educational practice of the science of learning and development. Appl Dev Sci, 24(2), 97-140. https://doi.org/0.1080/108886 91.2018 .1537791

Dewey, J. (1933). How we think: A restatement of the relation of reflective thinking to the educative process. D.C. Heath.
Di Paolo, E., Cuffari, E., \& De Jaegher, H. (2018). Linguistic bodies. The continuity between life and language. MIT Press. https://doi.org/ 10.7551/mitpress/11244.001.0001

Eyler, J. (2009). The power of experiential education. Liberal Education, 95(4), 24-31.

Flanagan, C., \& Levine, P. (2010). Civic engagement and the transition to adulthood. The Future of Children, 20(1), 159-179. https://doi. org $/ 10.1353 /$ foc. 0.0043

Gee, R. I., \& Nucci, L. (2019). From peer discourse to critical moral perspectives: Teaching for engaged reasoning. Precollege Philosophy and Public Practice, 1, 58-74. https://doi.org/ 10.5840/p4201810242

Gentner, D., \& Grudin, J. (1985). The evolution of mental metaphors in psychology: A 90-year retrospective. The American Psychologist, 40(2), 181-192.https://doi.org/10.1037/0003066X.40.2.181

Glick, J. (1992). Werner's relevance for contemporary developmental psychology. Developmental Psychology, 28(4), 558-565. https:// doi.org/10.1037/0012-1649.28.4.558

Hanks, W. (1996). Language and communicative practices. Taylor and Francis.

Herrenkohl, L. R., \& Mertl, V. (2010). How students come to be, know, and do: A case for a road view of learning. Cambridge University Press. CBO9780511777608 https://doi.org/10.1017/

Huber, M. T., \& Hutchings, P. (2004). Integrative learning: Mapping the terrain. Association of American Colleges and Universities.

Huber, M. T., Hutchings, P., \& Gale, R. (2005). Integrative learning for liberal education. Peer Review: Emerging Trends and Key Debates in Undergraduate Education, 7(3-4), 4-7. https://www.aacu.org/publications-research/periodicals/integrative-learning-liberal-education

Humphreys, D. (2005). Why integrative learning? Why now? Peer Review: Emerging Trends and Key Debates in Undergraduate Education, 7(4), 30-31. https://www.aacu.org/publications-research/periodicals/why-integrative-learning-why-now 
James, W. (1905). The experience of activity. Psychological Review, 12(1), 1-17. https://doi. org/10.1037/h0070340

Jantsch, E. (1972). Towards interdisciplinarity and transdisciplinarity in education and innovation. In L. Apostel (Ed.), Interdisciplinarity: problems of teaching and research in universities (pp. 97-121). Organization for Economic Cooperation and Development.

Kehm, B. (2010). Quality in European higher education: The influence of the Bologna process. Change. The Magazine of Higher Learning, 42(3), 40-46. https://doi.org/10.1080/ 00091381003704677

Klein, J. T. (2009). Unity of knowledge and transdisciplinarity: Contexts of definition, theory and the new discourse of problem solving. In G. H. Hardon (Ed.), Unity of knowledge in transdisciplinary research for sustainable development (pp. 35-69). EOLSS Publishers.

Klein, J. T., Grossenbacher-Mansuy, W., Häberli, R., Bill, A., Scholz, R. W., \& Welti, M. (Eds.) (2001). Transdisciplinarity: Joint problem solving among science, technology, and society: an effective way for managing complexity. Birkhäuser. https://doi.org/10.1007/9783-0348-8419-8

Kockelmans, J. (1979). Why interdisciplinarity? In J. J. Kockelmans (Ed.), Interdisciplinarity and higher education (pp. 123-160). Pennsylvania State University Press.

Kuhn, D. (2019). Critical thinking as discourse. Human Development, 62(3), 146-164. https:// doi.org/10.1159/000500171

Lakoff, G., \& Johnson, M. (1980). Metaphors we live by. University of Chicago Press.

Lave, J., \& Wenger, E. (1991). Situated learning: Legitimate peripheral participation. Cambridge University Press. https://doi.org/ 10.1017/CBO9780511815355

Lerner, R. M. (2016). Complexity embraced and complexity reduced: A Tale of two approaches to human development. Human Development, 59(4), 242-249. https://doi.org/ $10.1159 / 000452113$

Magolda, M. B. B. (2008). Three elements of selfauthorship. Journal of College Student Development, 49(4), 269-284. https://doi.org/ $10.1353 /$ csd.0.0016

Magolda, M. B. B. (2009). The activity of meaning making: A holistic perspective on college student development. Journal of College Student Development, 50(6), 621-639. https://doi. org/10.1353/csd.0.0106

Magolda, M. B., \& Taylor, K. (2016). Developing self-authorship in college to navigate emerging adulthood. In J. J. Arnett (Ed.), The Oxford handbook of emerging adults (pp. 299-315). Oxford University Press.

McAdams, D. P. (2013). The psychological self as actor, agent, and author. Perspectives on Psychological Science, 8(3), 272-295. https://doi. org/10.1177/1745691612464657

McAdams, D. P. (2016). Life authorship in emerging adulthood. In J. J. Arnett (Ed.), The Oxford handbook of emerging adults (pp. 438-448). Oxford University Press.
Mittelstrass, J. (2011). On transdisciplinarity. Trames, 15(4), 329-338. https://doi.org/ 10.3176/tr.2011.4.01

Moon, J., Michaels, S. \& Reiser, B. (2012, November 30 ). Science standards require a teacherlearning rethink. Education Week. https:// www.edweek.org/ew/articles / 2012/11/30/13moon.h32.html

Moore, D. (2013). Engaged learning in the academy. Palgrave Macmillan. https://doi. org/10.1057/9781137025197

Mueller, U. \& Newman, J. L. (2008). The body in action: perspectives on embodiment and development. In W. F. Overton, U. Mueller, \& J. L. Newman (Eds.), Developmental perspectives on embodiment and consciousness (pp. 313-342). Lawrence Erlbaum Associates/ Taylor and Francis Group.

Murray, J., \& Arnett, J. J. (Eds.) (2019). Emerging adulthood and higher education: A new student development paradigm. Routledge. https://doi.org/10.4324/9781315623405

Nelson, K. (2017). The cultural basis of language and thought in development. In N. Budwig, E. Turiel, \& P. Zelazo (Eds.), New perspectives on human development (pp. 402-424). Cambridge University Press. https://doi.org/ 10.1017/CBO9781316282755.022

Nucci, L. (2016, July 26). Character: A multi-faceted developmental system [Keynote address]. Workshop on Character Education for The National Academies of Sciences, Washington, D.C

Nucci, L., Creane, M. W., \& Powers, D. W. (2015). Integrating moral and social development within middle school social studies: A social cognitive domain approach. Journal of Moral Education, 44(4), 479-496. https://doi.org/ 10.1080/03057240.2015.1087391

Osher, D., Cantor, P., Berg, J., Steyer, L., \& Rose, T. (2020). Drivers of human development: How relationships and context shape learning and development. Applied Developmental Science, 24(1), 6-36. https://doi.org/10.1080/108 88691.2017 .1398650

Overton, W. F. (2013). Relationism and relational developmental systems: A paradigm for developmental science in the post-Cartesian era. Advances in Child Development and Behavior, 44, 21-64. https://doi.org/10.1016/B978-012-397947-6.00002-7

Overton, W. F. (2015). Processes, relations, and relational-developmental-systems. In R. Lerner (Ed.), Handbook of child psychology and developmental science (Vol. 1, pp. 9-62). Wiley. https://doi.org/10.1002/9781118963418. childpsy 102

Overton, W. F., Mueller, U., \& Newman, J. L. (Eds.) (2008). Developmental perspectives on embodiment and consciousness. Lawrence Erlbaum Associates/Taylor and Francis Group.

Parks, S. D. (2000). Big questions, worthy dreams: Mentoring young adults in their search for meaning, purpose, and faith. Jossey-Bass.

Piaget, J. (1954). The construction of reality in the child (M. Cook, Trans.). Basic Books. https:// doi.org/10.1037/11168-000
Piaget, J. (1967). Six psychological studies. Random House.

Piaget, J. (1972). The epistemology of interdisciplinary relationships. In L. Apostel, G. Berger, A. Briggs, \& G. Michaud (Eds.), Interdisciplinarity: Problems of teaching and research in universities (pp. 127-139). Organization for Economic Cooperation and Development.

Piaget, J. (1974/1980). Adaptation and intelligence: organic selection and phenocopy. University of Chicago Press.

Reichert, S., \& Tauch, C. (2005, May 20). Trends $I V$ : European universities implementing Bologna. European University Association.

Reiser, B. \& Tabak, I. (2014). Scaffolding. In K. Sawyer (Ed.), The Cambridge handbook of the learning sciences (pp. 44-62). Cambridge University Press.

Resnick, L. (1987). The 1987 presidential address: Learning in school and out. Educational Researcher, 16(9), 13-20.

Rogoff, B. (1995). Observing sociocultural activity on three planes: Participatory appropriation, guided participation, and apprenticeship. In J. Wertsch, P. Rio, \& A. Alvarez (Eds.), Sociocultural studies of mind (Learning in doing: Social, cognitive and computational perspectives, pp. 139-164). Cambridge University Press. https://doi.org/10.1017/ CBO9781139174299.008

Sawyer, K. (2014). The Cambridge handbook of the learning sciences. Cambridge University Press. https://doi.org/10.1017/ CBO9781139519526

Saxe, G. B. (2014). Cultural development of mathematical ideas: Papua New Guinea studies. Cambridge University Press.

Scardamalia, M., \& Bereiter, C. (2006). Knowledge building: Theory, pedagogy and technology. In R. K. Sawyer (Ed.), The Cambridge handbook of the learning sciences (pp. 97115). Cambridge University Press.

Scardamalia, M., \& Bereiter, C. (2014). Knowledge building and knowledge creation: Theory, pedagogy, and technology. In K. Sawyer (Ed.), The Cambridge handbook of the learning sciences (pp. 397-417). Cambridge University Press. https://doi.org/10.1017/ CBO9781139519526.025

Schwartz, S. J., Zamboanga, B. L., Luyckx, K., Meca, A., \& Ritchie, R. (2016). Identity in emerging adulthood: Reviewing the field and looking forward. In J. J. Arnett (Ed.), The Oxford handbook of emerging adults (pp. 401420). Oxford University Press.

Shove, E., \& Rip, A. (2000). Users and unicorns: A discussion of mythical beasts. Science Public Policy, 27(3), 175-182. https://doi.org/ $10.3152 / 147154300781781959$

Sokol, B. W., Chandler, M. J., Hammond, S., McEnerney, K., \& Marle, P. (2018). The "spaces in-between": Applying relational developmental systems theory to identity and moral character. In A. S. Dick \& U. Müller (Eds.), Advancing developmental science: Philosophy, theory, and method (pp. 235-248). Routledge. https:// doi.org/10.4324/8791315174686-19
Conceptual Frameworks Guiding

Developmental Research and Practice
Human Development 2021;65:1-18 DOI: $10.1159 / 000514553$ 
Starmans, C., \& Friedman, O. (2012). The folk conception of knowledge. Cognition, 124(3), 272-283. https://doi.org/10.1016/j.cognition.2012.05.017

Strange, C. (2019). Creating campus environments for emerging adults. In J. Murray \& J. Arnett (Eds.), Emerging adulthood and higher education: A new student development paradigm (pp. 143-157). Routledge.

Strange, C., \& Banning, J. (2015). Designing for learning: Creating campus environments for student success. Jossey-Bass.

Taylor, C. (1989). Embodied agency. In H. Pietersma (Ed.), Merleau-Ponty: Critical essays (pp. 1-22). University Press of America.
Tudge, J. R. H., Payir, A., Mercon-Vargas, E., Cao, H., Liang, Y., Li, J., \& O’Brien, L. (2016). Still misused after all these years? A reevaluation of the uses of Bronfenbrenner's bioecological theory of human development. Journal of Family Theory \& Review, 8(4), 427-445. https://doi.org/10.1111/jftr.12165

Valsiner, J. (1998). The guided mind: A sociogenetic approach to personality. Harvard University Press.

Vygotsky, L. S. (1978). Mind in society: The development of higher psychological processes. Harvard University Press.

Wenger, E. (1998). Communities of practice. Learning, meaning and identity. Cambridge University Press. https://doi.org/10.1017/ CBO9780511803932
Werner, H., \& Kaplan, B. (1963). Symbol formation: An organismic-developmental approach to language and the expression of thought. John Wiley \& Sons.

Witherington, D. C., Overton, W. F., Lickliter, R., Marshall, P. J., \& Narvaez, D. (2018). Metatheory and the primacy of conceptual analysis in developmental science. Human Development, 61(3), 181-198. https://doi.org/10.1159/ 000490160

Wortham, S. (2010). Redefining the gap between theory and practice: Should anthropologists try to change the world? Anthropology News, 51(6), 31-32. https://doi.org/10.1111/ j.1556-3502.2010.51631.x 